\title{
Gold Nanoparticle-Bioconjugated Aminoguanidine Inhibits Glycation Reaction: An In Vivo Study in a Diabetic Animal Model
}

\author{
Saheem Ahmad ${ }^{1},{ }^{1}$ Mohd. Sajid Khan, ${ }^{2,3}$ Sultan Alouffi ${ }^{10},{ }^{1,4}$ Saif Khan, ${ }^{5}$ Mahvish Khan, ${ }^{6}$ \\ Rihab Akashah, ${ }^{1}$ Mohammad Faisal $\left({ }^{1},{ }^{7}\right.$ and Uzma Shahab ${ }^{8}{ }^{8}$ \\ ${ }^{1}$ Department of Clinical Laboratory Sciences, College of Applied Medical Sciences, University of Hail, Saudi Arabia \\ ${ }^{2}$ Department of Biosciences, Integral University, Lucknow, India \\ ${ }^{3}$ Department of Biochemistry, Faculty of Life Sciences, Aligarh Muslim University, Aligarh 202002, India \\ ${ }^{4}$ Molecular Diagnostic \& Personalized Therapeutic Unit, University of Hail, Saudi Arabia \\ ${ }^{5}$ Department of Basic Dental and Medical Sciences, College of Dentistry, University of Hail, Ha'il 2440, Saudi Arabia \\ ${ }^{6}$ Department of Biology, College of Science, University of Hail, Ha'il 2440, Saudi Arabia \\ ${ }^{7}$ Department of Botany and Microbiology, College of Science, King Saud University, Saudi Arabia \\ ${ }^{8}$ Department of Biotechnology, Khwaja Moinuddin Chishti Language University, Sitapur-Hardoi Bypass Road, \\ Lucknow 226013, India
}

Correspondence should be addressed to Saheem Ahmad; ahmadsaheem@gmail.com and Uzma Shahab; uzmashahab@gmail.com

Received 15 February 2021; Revised 25 April 2021; Accepted 3 May 2021; Published 13 May 2021

Academic Editor: Andrey Cherstvy

Copyright (C) 2021 Saheem Ahmad et al. This is an open access article distributed under the Creative Commons Attribution License, which permits unrestricted use, distribution, and reproduction in any medium, provided the original work is properly cited.

Proteins undergo glycation resulting in the generation of advanced glycation end products (AGEs) that play a central role in the onset and advancement of diabetes-associated secondary complications. Aminoguanidine (AG) acts as an antiglycating agent by inhibiting AGE generation by blocking reactive carbonyl species (RCS) like, methylglyoxal (MGO). Previous studies on antiglycating behavior of AG gave promising results in the treatment of diabetes-associated microvascular complications, but it was discontinued as it was found to be toxic at high concentrations $(>10 \mathrm{mmol} / \mathrm{L})$. The current article aims at glycation inhibition by conjugating gold nanoparticles (Gnp) with less concentration of AG (0.5-1.0 mmol/L). The HPLC results showed that AG-Gnp fairly hampers the formation of glycation adducts. Moreover, the in vivo studies revealed AG-Gnp mediated inhibition in the production of total-AGEs and $-N^{\varepsilon}$-(carboxymethyl)lysine (CML) in the diabetic rat model. This inhibition was found to be directly correlated with the antioxidant parameters, blood glucose, insulin, and glycosylated hemoglobin levels. Furthermore, the histopathology of AG-Gnp-treated rats showed good recovery in the damaged pancreatic tissue as compared to diabetic rats. We propose that this approach might increase the efficacy of AG at relatively low concentrations to avoid toxicity and might facilitate to overcome the hazardous actions of antiglycating drugs.

\section{Introduction}

In diabetes mellitus, hyperglycemia-mediated glycation starts with the nucleophilic addition between the carbonyl group of reducing sugars with free amino groups of proteins [1-3]. The glycation reaction proceeds with the formation of reversible Schiff's bases, to stable ketoamines or Amadori products, which finally lead to the formation of advanced glycation end products (AGEs) $[4,5]$. Moreover, autoxidation of glucose and glycoxidation of proteins give rise to reactive oxygen species (ROS) that lead to the generation of reactive carbonyl species (RCS) or dicarbonyls such as glyoxal (GO), methylglyoxal (MGO), and 3-deoxyglucosone (3-DG) [6, 21]. Furthermore, shunting of excess glucose in the polyol pathway and glycolysis too results in the generation of RCS [7-9].

In the physiological system, levels of reducing sugars and RCS together determine the type of AGEs that are generated during glycation reaction $[10,11]$. The in vivo formation and accretion of AGEs such as $-N^{\varepsilon}$-(carboxymethyl)lysine (CML), $-N^{\varepsilon}$-(carboxyethyl)lysine (CEL), $\varepsilon$-fructosyl-L-lysine (FL), 
argpyrimidine, and pentosidine play a decisive role in the pathogenesis of diabetes-associated secondary complications and cancer $[12,13]$. Although glycation is a slow process but increases several folds during persistent hyperglycemia [14], plasma amines react with the carbonyl group of sugars, Amadori products, and RCS, thereby preventing the nucleophilic addition reaction between $>\mathrm{C}=\mathrm{O}$ and $-\mathrm{NH}_{2}$ [15]. Furthermore, antioxidants quench glycation-derived ROS, whereas transport proteins such as ceruloplasmin bind with the transition metal ions and prevent them to participate in autoxidation and glycoxidation reactions $[16,17]$.

Aminoguanidine (AG), a hydrazine compound, is an antiglycation drug that inhibits AGE generation via blocking the carbonyl groups on reducing sugars, Amadori products, and RCS $[18,19]$. Earlier investigations on AG gave promising results in the treatment of diabetes-associated microvascular complications such as retinopathy and nephropathy but were later on found to be toxic at higher concentrations ( $>10 \mathrm{mM})$, and hence for safety concerns, the human clinical trials were halted [20]. However, several in vitro investigations and animal studies have shown AG-mediated prevention of diabetes-induced deterioration in diabetes-associated cardiovascular diseases [21].

In the light of the aforementioned accounts, this study is aimed at exploiting the preventive effects of AG on glycation and diabetes, by using gold nanoparticle- (Gnp-) bioconjugated AG (AG-Gnp) at low concentrations which is nontoxic. Gold nanoparticles (Gnp) are among the most commonly used nanostructures in biological applications [22, 23]. Gnp increase drug effectiveness due to the virtue of their biocompatibility, surface area, and surface functionalization and hence are frequently used in the cure of chronic lymphocytic leukemia $[24,25]$. Gnp can easily conjugate with different globular proteins like BSA and cytochrome c [26]. Interestingly, Gnp has been utilized by several investigators in determining the glycation status of the proteins [27]. Furthermore, diabetic rat models were designed to check the efficacy of AG-Gnp in vivo by measuring certain markers of glycation including total AGEs and CML-AGEs, and antioxidant status of the diabetic and treated animals as well.

\section{Materials and Methods}

\subsection{Materials}

2.1.1. Chemicals. Methylglyoxal (MGO), human serum albumin (HSA), aminoguanidine (AG), alloxan, and $\alpha-\mathrm{NADPH}$ were obtained from Sigma-Aldrich. The lactate dehydrogenase (LDH) kit was purchased from Biomedical Research Services (Buffalo, NY, USA). 5,5'-Dithio-bis-[2-nitrobenzoic acid] (DTNB) was bought from Pierce Biotechnology (Rockford, IL). All other reagents and solvents were of the highest analytical grade which were obtained from HiMedia, Mumbai, India.

2.1.2. Animals. The male Wistar rats (200-220 gm) were purchased from the Central Drug Research Institute, Lucknow, India. The animals were kept in a 12/12-hour light and dark cycle in temperature-controlled cages with free access to normal diet and water. The study was approved by “The Institutional Animal Ethics Committee" of Integral University, Lucknow, India, with approval number: IU/Biotech/Project/CPCSEA/13/12.

\subsection{Methods}

2.2.1. In Vitro Synthesis of Gold Nanoparticles and Its Bioconjugation. Gold nanoparticles (Gnp) were prepared by the method described earlier with slight modifications [28]. The Gnp were conjugated with aminoguanidine by using 1-ethyl-3-(3-dimethylaminopropyl)-carbodiimide (EDC) $[29,30]$.

2.2.2. Preparation of Glycated Samples. The glycated samples were prepared as described previously [31, 32]. In brief, $20 \mathrm{mg} \mathrm{mL}^{-1} \mathrm{HSA}$ was incubated with $10 \mathrm{mmol} / \mathrm{L}$ methylglyoxal (MGO) in $20 \mathrm{mmol} / \mathrm{L}$ phosphate buffer saline (PBS) of $\mathrm{pH}$ 7.4. The reaction mixtures were kept at $37^{\circ} \mathrm{C}$ for 20 days under strict sterile conditions to avoid any microbial growth by adding $0.02 \%$ sodium azide. Blanks, HSA $\left(20 \mathrm{mg} \mathrm{mL}^{-1}\right)$, and MGO $(10 \mathrm{mmol} / \mathrm{L})$ were also incubated separately for the same time.

2.2.3. Reverse Phase-High Performance Liquid Chromatography (RP-HPLC) Analysis. RP-HPLC analysis was performed on a Hitachi analytical HPLC system comprising of L-7100 lowpressure gradient pumps, L-7200 sequential autosampler, and a high sensitivity diode array detector (190-800 nm) and was managed by D-7000 HPLC system manager software. Reverse phase-HPLC contains a c-18 column for the separation of samples. Mobile phases $\mathrm{A}$ and $\mathrm{B}$ were $0.1 \mathrm{~mol} / \mathrm{L}$ aqueous ammonium acetate and 100\% HPLC analytical grade acetonitrile, respectively. A stepwise elution of $90: 10$ of B:A of the mobile phases was applied for $15 \mathrm{~min}$ followed by 10:90 of $\mathrm{B}$ : A of mobile phases for another $15 \mathrm{~min}$ in the entire analysis. There are $10 \%$ acetonitrile and $90 \% \mathrm{H}_{2} \mathrm{O}$ with $0.1 \% \mathrm{HCOOH}$ as solvent $\mathrm{A}$ and $90 \%$ acetonitrile and $10 \% \mathrm{H}_{2} \mathrm{O}$ with $0.1 \%$ $\mathrm{HCOOH}$ as solvent B. Gradients started from $0 \%$ B to $60 \%$ $\mathrm{B}$ after $30 \mathrm{~min}$, then $90 \% \mathrm{~B}$ after another $15 \mathrm{~min}$ and then again brought to $0 \% \mathrm{~B}$. Before HPLC analysis, all the solvents were filtered with $0.45 \mu \mathrm{m}$ membranes (Millipore, USA) and degassed for $10 \mathrm{~min}$ before use. All the profiles were obtained at a fixed wavelength of $280 \mathrm{~nm}$.

In another set of experiments of HPLC, determination of $-N^{\varepsilon}$-(carboxymethyl)lysine (CML) by HPLC was done as described earlier [33]. In brief, $10 \mathrm{~mL}$ of $35 \% \mathrm{HCl}$ was used to hydrolyze the $10 \mathrm{mg}$ sample at $105^{\circ} \mathrm{C}$. After hydrolysis, the sample was centrifuged at $14000 \mathrm{rpm}$ for 15 minutes after cooling at room temperature. $10 \mathrm{~mL}$ of methanol and $20 \mathrm{~mL}$ of deionized water (DW) was used to prewet Sep-Pak C18 cartridge (Waters, MA, U.S.A.), and supernatant $(1 \mathrm{~mL})$ was applied to it and subsequently eluted with $3 \mathrm{M} \mathrm{HCl}$ $(10 \mathrm{~mL})$. The eluted sample $(20 \mu \mathrm{L})$ and o-phthalaldehyde (OPA) reagent $(20 \mu \mathrm{L})$ were mixed vigorously. After 3 minutes, derivatized hydrolysate $(20 \mu \mathrm{L})$ was analyzed at $32^{\circ} \mathrm{C}$ with an analytical column $(4.6 \times 250 \mathrm{~mm})$. The mobile phase was composed of (A) DW and (B) methanol, and the gradient was linear from 0 to $100 \% \mathrm{~B}$ in $16 \mathrm{~min}$. The OPA derivatives were excited at $340 \mathrm{~nm}$, and the emission was recorded at $440 \mathrm{~nm}$ on an Agilent Cary Eclipse Fluorescence 
Spectrometer. The peak retention time of the CML standard (PolyPeptide Lab., CA, USA) was used to identify the peak of sample constituents.

2.2.4. Lactate Dehydrogenase (LDH) Assay. Lactate dehydrogenase assay was done by using the LDH kit (Biomedical Research Services) as described earlier [34]. In brief, the blood was centrifuged at $400 \mathrm{rpm}$ to obtain platelet-rich plasma. AG (10 mmol/L) and AG-Gnp (0.5 and $1.0 \mathrm{mmol} / \mathrm{L})$ were incubated for $2 \mathrm{hr}$ with platelets. The cytotoxicity of AG and AG-Gnp was measured by the release of $\mathrm{LDH}$ from platelets lysed with $1 \%$ Triton X-100.

\subsubsection{Alloxan-Induced Diabetes in Male Wistar Rats. Type 1} diabetes in Wistar rats was induced by giving an intraperitoneal single dose of alloxan $(100 \mathrm{mg} / \mathrm{kg})$ after $24 \mathrm{hr}$ of fasting. The alloxan was dissolved in $0.9 \% \mathrm{NaCl}$. The animals were housed in a standard laboratory condition, 12-hour lightdark cycle, constant temperature, and easy access to food and water. The induction of hyperglycemia was confirmed one week after treatment. Rats with a blood glucose level of $\geq 11 \mathrm{mmol} / \mathrm{L}$ were considered diabetic [35].

2.2.6. Measurement of AGE and CML Levels in Diabetic and AG-Gnp-Treated Groups. Total AGEs in the serum samples of experimental rats were measured by using the ELISA kit from Cell Biolabs (San Diego, CA). Anti-AGE polyclonal antibody and horseradish peroxidase-conjugated secondary antibody were used to probe AGEs, though the total AGE detection and inhibition in the serum samples are not precise by this method. However, we performed this study just to see the overall AGE inhibition as a result of AG-Gnp. The AGE content was determined by comparing with AGE-bovine serum albumin (BSA) standard curve ranging from 0.25 to $5 \mu \mathrm{g} \mathrm{mL}^{-1}$. The absorbance was read at $450 \mathrm{~nm}$ on a BioRad Multiplate Reader (Bio-Rad, Laboratories, CA) against BSA standard. AGE-BSA contains pentosidine, CML, and other heterogenous AGE structures.

Similarly, $-N^{\varepsilon}$-(carboxymethyl)lysine in the serum samples was also measured by using the ELISA kit from Cell Biolabs (San Diego, CA). The CML contents were determined by comparing it with CML-BSA standard curve ranging from 0.035 to $2.2 \mathrm{ng} \mathrm{mL}^{-1}$. The rest of the procedure was the same as that of the total AGE estimation [36].

2.2.7. Effect of AG and AG-Gnp on Blood Glucose, Triglycerides, and Insulin in a Diabetic Rat Model. Glucose levels were estimated to ensure induction of T1DM in experimental rats. Six rats were randomly selected as a normal group, and the rest were used to induce a diabetic model. AG $(10 \mathrm{mM} / \mathrm{kg}$ body weight) was used as control and administered intraperitoneally for 2 weeks on daily basis. The concentration of AG-Gnp was $0.5 \mathrm{mmol} / \mathrm{L}$ and $1.0 \mathrm{mmol} / \mathrm{L}$ per $\mathrm{kg}$ body weight. The AG and AG-Gnp treatment was further maintained by including the drugs in drinking water for two more weeks. After four weeks of AG and AG-Gnp administration, blood was drawn from the oculo-orbital vein after $12 \mathrm{hr}$ fasting and the levels of insulin, glucose, and triglycerides were determined [37, 38].
2.2.8. Effect of $A G$ and AG-Gnp on the Antioxidant Defense System and Pancreatic Exocrine Function in Diabetic Rats. The diabetic rats were arbitrarily segregated into four groups ( $n=8$ in each group): (a) diabetic, (b) diabetic + AG $(10 \mathrm{mM} / \mathrm{kg})$, (c) diabetic+AG-Gnp $(0.5 \mathrm{mM} / \mathrm{kg})$, and (d) diabetic+AG-Gnp (1.0 mM/kg), respectively. After four weeks of drug administration, animals fainted with ethyl carbamate $(1.4 \mathrm{~g} / \mathrm{kg}$, i.p.) and the collected blood was centrifuged at $3000 \mathrm{rpm}$ for $5 \mathrm{~min}$. The concentrations of malondialdehyde (MDA), reduced glutathione (GSH), and the activities of superoxide dismutase (SOD), catalase (CAT), and amylase (AMS) in the sera were measured. After blood collection, the rats were sacrificed by decapitation and the pancreatic tissues were removed for histological investigations.

2.2.9. Histopathology of Diabetic and AG- and AG-GnpTreated Rat Pancreas. The effect of diabetes on animal tissue was examined by histopathology of rat pancreas as described previously [39]. In brief, pancreatic tissue fragments were fixed in $10 \%$ formalin solution, embedded in paraffin, and stained with hematoxylin and eosin. The tissue slides were assessed by bright-field microscopy (Carl Zeiss, Axiolab 5, Germany).

2.2.10. Statistical Analysis. The results were evaluated by using analysis of variance (ANOVA) followed by NewmanKeuls multiple comparisons. In general, the null hypothesis used for all analyses was that the factor does not influence the measured variables, and significance was accepted at the over $95 \%$ confidence level.

\section{Results}

3.1. Absorption Profile of Aminoguanidine-Bioconjugated Gold Nanoparticles. The absorption spectrum of aminoguanidine gold nanoparticles (Gnp-HSA-AG) showed a peak at $529 \mathrm{~nm}$ that corresponds to AG-gold nanoparticles (AGGnp) with a blue shift suggesting its binding to Gnp.

3.2. Cytotoxicity Assay. Cytotoxicity assay showed no significant increase in $\mathrm{LDH}$ leakage after incubation of platelets with 0.5 and $1.0 \mathrm{mmol} / \mathrm{L} \mathrm{AG-Gnp}$. With $0.5 \mathrm{mmol} / \mathrm{L} \mathrm{AG-}$ Gnp, the release of $\mathrm{LDH}$ was $3.91 \pm 0.56 \%$, whereas, with $1.0 \mathrm{mmol} / \mathrm{L}$ concentration of AG-Gnp, it was $4.13 \pm 0.48 \%$. However, at $10 \mathrm{mmol} / \mathrm{L}$ concentration of $\mathrm{AG}$, the increase in $\mathrm{LDH}$ was found to be quite high, i.e., $7.13 \pm 1.10 \%$. It is important to note that more than $4 \pm 0.51 \%$ of $\mathrm{LDH}$ leakage is supposed to be toxic at this concentration. The results are summarized in Table 1.

3.3. RP-HPLC Analysis. The samples to be analyzed were hydrolyzed with $6 \mathrm{~N} \mathrm{HCl}$ for $24 \mathrm{hr}$ at $110^{\circ} \mathrm{C}$. The hydrolyzed samples were then filtered by a $0.42 \mu \mathrm{M}$ Millex filter for ultrafiltration. The HPLC elution profiles of the hydrolysated HSA, HSA-MGO, and HSA-MGO with AG-Gnp (1.0 mmol/L) are shown in Figure 1. HSA was eluted alone at 14.2 minutes (peak a), whereas MGO did not show a separate peak at $280 \mathrm{~nm}$. Upon glycation, i.e., in HSA-MGO, a sequence of newly emerged peaks (b, $c, d$, and e) represents the formation of AGEs, whereas peak "a" that represents unmodified HSA decreased simultaneously. This indicates that HSA has lost 
TABLE 1: Effect of AG and AG-Gnp on total lactate dehydrogenase $(\mathrm{LDH})$ released in the incubation medium from HSA-MGO mixtures.

\begin{tabular}{lcccc}
\hline $\begin{array}{l}\text { Incubation } \\
\text { time (min.) }\end{array}$ & Control & $\begin{array}{c}\mathrm{AG} \\
(10 \mathrm{mM})\end{array}$ & $\begin{array}{c}\text { AG-Gnp } \\
(0.5 \mathrm{mM})\end{array}$ & $\begin{array}{c}\text { AG-Gnp } \\
(1.0 \mathrm{mM})\end{array}$ \\
\hline 0 & $0.00 \pm 0.00$ & $0.00 \pm 0.00$ & $0.00 \pm 0.00$ & $0.00 \pm 0.00$ \\
30 & $0.58 \pm 0.32$ & $2.97 \pm 0.43$ & $1.27 \pm 0.22$ & $1.25 \pm 0.27$ \\
60 & $1.28 \pm 0.24$ & $4.29 \pm 0.43$ & $2.33 \pm 0.33$ & $2.15 \pm 0.24$ \\
90 & $1.46 \pm 0.21$ & $5.93 \pm 0.14$ & $3.35 \pm 0.29$ & $3.29 \pm 0.26$ \\
120 & $2.65 \pm 0.24$ & $7.13 \pm 0.23$ & $3.91 \pm 0.35$ & $4.13 \pm 0.41$ \\
\hline
\end{tabular}

Results are presented as mean \pm SD.

its native state upon glycation with MGO. The additional peaks b, c, d, and e in HSA-MGO were eluted at the retention time of 13.4, 12.1, 9.6, and 7.8 minutes, respectively.

The elution profile of HSA-MGO with AG-Gnp $(1.0 \mathrm{mmol} / \mathrm{L})$ showed only 3 peaks (b, c, and e) with decreased intensities that correspond to AGEs. Peak "d" was absent in the presence of AG-Gnp which was one of the AGEs formed in MGO-glycated HSA (HSA-MGO). The decreased intensities for peaks b, c, and e matched to $84.2 \pm 4.2 \%, 68.7 \pm 5.4 \%$, and $70 \pm 3.5 \%$, respectively. These results confirmed that fewer AGE species were formed in the presence of AG-Gnp at $1.0 \mathrm{mmol} / \mathrm{L}$ concentration.

The antiglycation effect of AG-Gnp on the level of representative AGE marker, i.e., carboxymethyl lysine (CML) is shown in Figure 2. The AG treatment significantly inhibited $(34.5 \pm 1.8 \%)$ the formation of CML to nontreated glycation control (HSA-MGO). When treatment was done with $0.5 \mathrm{mmol} / \mathrm{L}$ AG-Gnp, the inhibition was as higher as $48 \pm$ $2.6 \%$ in comparison to AG, whereas, with $1.0 \mathrm{mmol} / \mathrm{L}$ AGGnp, the CML inhibition was found to be $72.1 \pm 3.2 \%$.

3.4. Effects of AG and AG-Gnp on Blood Glucose, Triglycerides, and Insulin Profile in a Diabetic Rat Model. The alloxanmediated damage suffered by pancreatic $\beta$-cells resulted in high blood glucose and triglyceride levels and reduced insulin levels in diabetic groups with respect to normal control groups. The administration of AG $(10 \mathrm{mM} / \mathrm{kg})$ and AG-Gnp $(0.5$ and $1.0 \mathrm{mM} / \mathrm{kg}$ ) reduced the blood glucose and triglyceride levels and increased the insulin levels. The AG-Gnp- (0.5 and $1.0 \mathrm{mmol} / \mathrm{L}$ ) treated group of animals was higher in inhibiting the levels of blood glucose and triglycerides and enhancing the level of insulin than the AG group. The AG-Gnp group was able to rectify the above parameters in a dose-dependent manner. The $1.0 \mathrm{mM} / \mathrm{kg}$ group of AG-Gnp was found to be more pronounced than the $0.5 \mathrm{mM} / \mathrm{kg}$ group of AG-Gnp, in reducing the levels of triglycerides and blood glucose and enhancing the level of insulin. Compared with diabetic or AG groups, AG-Gnp at $1.0 \mathrm{mM} / \mathrm{kg}$ groups exhibited a twofold increase in insulin levels, which suggests that AG-Gnp might exert some protective effect on the pancreatic tissues or $\beta$-cell function. The results are summarized in Table 2 .

3.5. Effects of $A G$ and AG-Gnp on Antioxidant Activity and Pancreatic Exocrine Function in a Diabetic Rat Model. Malondialdehyde (MDA) equivalent concentration in the dia- betic group $(4.23 \pm 0.89 \mathrm{nmol} / \mathrm{L})$ was higher than that in the control group $(2.45 \pm 0.68 \mathrm{nmol} / \mathrm{L})$, which reflects increased lipid peroxidation. However, with respect to the diabetic group, all the treated groups showed a reduction in MDA levels, i.e., AG $(10 \mathrm{mmol} / \mathrm{L})=3.27 \pm 0.98$, AG-Gnp ( $0.5 \mathrm{mmol} / \mathrm{L})=3.13 \pm 0.43$, and $A G-G n p(1.0 \mathrm{mmol} / \mathrm{L})=$ $2.87 \pm 0.42 \mathrm{nmol} / \mathrm{L}$, which indicates reduced lipid peroxidation. The superoxide dismutase (SOD) activity in the diabetic group $(201.9 \pm 21.7 \mathrm{U} / \mathrm{mL})$ was much higher than that in the normal group $(140.2 \pm 12.2 \mathrm{U} / \mathrm{mL})$. However, with respect to the diabetic group, all the treated groups showed a reduction in SOD activity, i.e., $\mathrm{AG}(10 \mathrm{mmol} / \mathrm{L})$ has $136.3 \pm 56.4$, AGGnp $(0.5 \mathrm{mmol} / \mathrm{L})$ recorded to be $130.2 \pm 43.6$, and AGGnp $(1.0 \mathrm{mmol} / \mathrm{L})$ found to be $136.6 \pm 25.2 \mathrm{U} / \mathrm{mL}$. The catalase (CAT) activity in the diabetic group $(1.48 \pm 0.83 \mathrm{U} / \mathrm{mL})$ was much lower than that in the normal group $(4.22 \pm 1.87$ $\mathrm{U} / \mathrm{mL}$ ). However, with respect to the diabetic group, all the treated groups showed an increase in CAT activity, i.e., AG $(10 \mathrm{mmol} / \mathrm{L})=3.21 \pm 1.14$, AG-Gnp $(0.5 \mathrm{mmol} / \mathrm{L})=3.9 \pm$ 1.45 , and AG-Gnp $(1.0 \mathrm{mmol} / \mathrm{L})=4.1 \pm 1.11 \mathrm{UmL}^{-1}$. The glutathione (GSH) activity in the diabetic group $\left(123.4 \pm 12.5 \mathrm{mg} \mathrm{dL}^{-1}\right)$ was lower than that in the normal group $\left(172.9 \pm 13.5 \mathrm{mg} \mathrm{dL}^{-1}\right)$. However, with respect to the diabetic group, all the treated groups showed an increase in GSH activity, i.e., AG $(10 \mathrm{mmol} / \mathrm{L})=155.8 \pm 42.3$, AG-Gnp $(0.5 \mathrm{mmol} / \mathrm{L})=167.8 \pm 34.6$, and $\mathrm{AG}-\mathrm{Gnp}(1.0 \mathrm{mmol} / \mathrm{L})=$ $178.1 \pm 34 \mathrm{mg} \mathrm{dL}^{-1}$. The pancreatic amylase (AMS) activity in the diabetic group $(617.3 \pm 58.4 \mathrm{U} / \mathrm{dL})$ was lower than that in the normal group $(719.8 \pm 23.7 \mathrm{U} / \mathrm{dL})$. However, in comparison to the diabetic group, all the treated groups showed an increase in AMS activity, i.e., AG $(10 \mathrm{mmol} / \mathrm{L})$ $=630.4 \pm 93.5$, AG-Gnp $(0.5 \mathrm{mmol} / \mathrm{L})=670.8 \pm 72.6$, and AG-Gnp $(1.0 \mathrm{mmol} / \mathrm{L})=701.4 \pm 68.5 \mathrm{U} / \mathrm{dL}$. The results are summarized in Table 3.

3.6. Determination of Total AGE and CML Contents. The AGE levels in the sera of normal control and diabetic rats were found to be $1.21 \pm 0.23$ and $5.83 \pm 0.45 \mu \mathrm{g} \mathrm{mL}^{-1}$, respectively. Upon treatment with $10 \mathrm{mmol} / \mathrm{L} \mathrm{AG}$, the levels of AGEs were $4.92 \pm 0.63 \mu \mathrm{g} \mathrm{mL}^{-1}$. However, the concentration of serum AGEs in the case of 0.5 and $1.0 \mathrm{mmol} / \mathrm{L}$ of AGGnp-treated diabetic rats showed $4.14 \pm 0.53$ and $3.21 \pm$ $0.71 \mu \mathrm{g} \mathrm{mL}^{-1}$, respectively. The decline in the level of the serum AGEs in the case of $0.5 \mathrm{mmol} / \mathrm{L}$ AG-Gnp was recorded to be $28.8 \pm 4.2 \%$, and when the concentration of AG-Gnp was further increased to $1.0 \mathrm{mmol} / \mathrm{L}$, the level of AGEs was further reduced to $44.9 \pm 5.7 \%$.

The CML is among the best-studied AGEs in the context of diabetes and its secondary complications. The CML levels in the sera of normal control and diabetic rats were $0.52 \pm$ 0.16 and $2.12 \pm 0.84 \mathrm{ng} \mathrm{mL}^{-1}$, respectively. Upon treatment with $10 \mathrm{mmol} / \mathrm{L}$ AG, the levels of CML were $2.01 \pm 0.23$ $\mathrm{ng} \mathrm{mL} \mathrm{m}^{-1}$, which is $5.1 \pm 0.70 \%$ less than the diabetic rats. However, the concentration of serum CML in the case of 0.5 and $1.0 \mathrm{mmol} / \mathrm{L}$ of AG-Gnp-treated diabetic rats showed $1.68 \pm 0.33$ and $1.23 \pm 0.18 \mathrm{ng} \mathrm{mL}^{-1}$, respectively. The drop in the level of the serum CML in the case of $0.5 \mathrm{mmol} / \mathrm{L}$ AGGnp was recorded to be $20 \pm 1.6 \%$, and when the concentration of AG-Gnp was further increased to $1.0 \mathrm{mmol} / \mathrm{L}$, the 


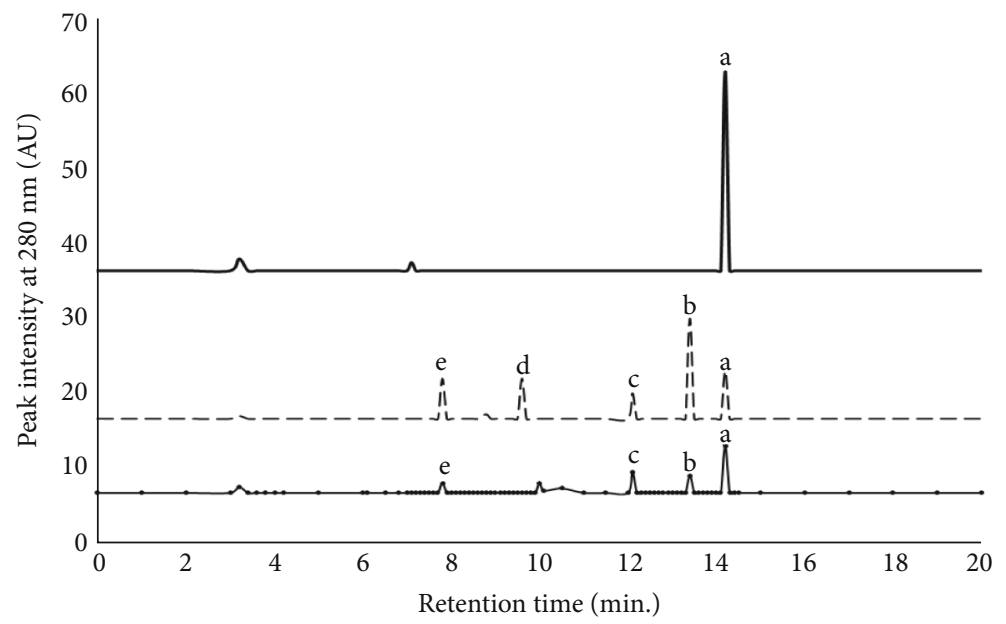

FIGURE 1: HPLC elution profiles of HSA with MGO mixtures after 15 days of incubation; HSA (-), HSA-MGO (--—), and HSA-MGO with $1.0 \mathrm{mM}$ AG-Gnp (-•--). UV absorbance was measured at $280 \mathrm{~nm}$ wavelength. All readings were taken in triplicates.

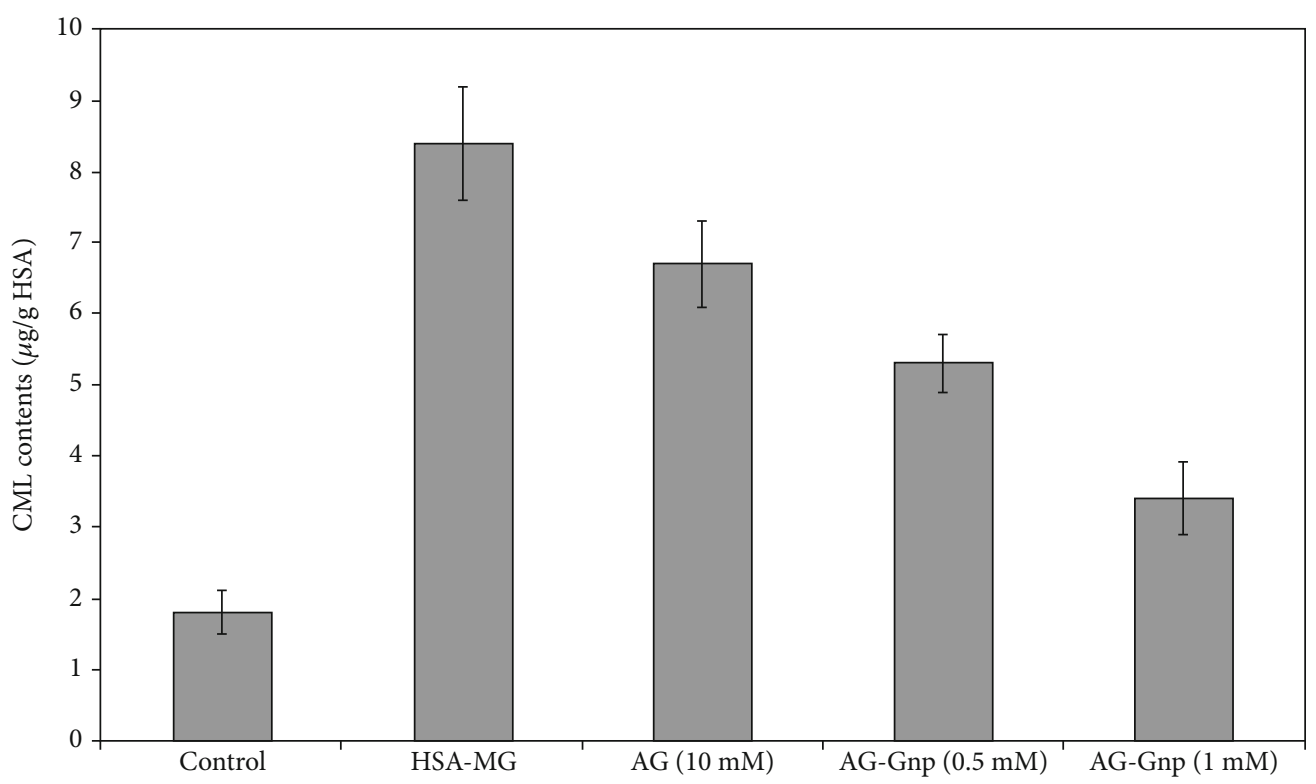

FIGURE 2: CML contents $\left(\mathrm{n} \mathrm{gm}^{-1}\right)$ in the reaction mixture of MGO-HSA mixtures. The inhibitions of the CML contents were measured using $10 \mathrm{mM}$ AG, $0.5 \mathrm{mM}$, and 1.0 mM AG-Gnp. All experiments were performed in triplicates.

TABLE 2: Effects of AG and AG-Gnp on blood glucose, triglycerides, and insulin in a diabetic rat model.

\begin{tabular}{lccc}
\hline Group & Glucose $\left(\mathrm{mmol} \mathrm{L}^{-1}\right)$ & Triglycerides $\left(\mathrm{mmol} \mathrm{L}^{-1}\right)$ & Insulin $\left(\mathrm{mmol} \mathrm{L}^{-1}\right)$ \\
\hline Control & $3.67 \pm 0.26$ & $1.48 \pm 0.23$ & $9.87 \pm 0.76$ \\
Diabetic & $16.8 \pm 1.13$ & $13.56 \pm 0.83$ & $3.23 \pm 0.42$ \\
Diabetic+AG $\left(10 \mathrm{mM} \mathrm{kg}^{-1}\right)$ & $10.13 \pm 0.48$ & $7.64 \pm 0.65$ & $4.55 \pm 0.29$ \\
Diabetic+AG-Gnp $\left(0.5 \mathrm{mM} \mathrm{kg}^{-1}\right)$ & $8.67 \pm 0.86$ & $5.88 \pm 0.53$ & $5.32 \pm 0.68$ \\
Diabetic+AG-Gnp $\left(1.0 \mathrm{mM} \mathrm{kg}^{-1}\right)$ & $7.32 \pm 0.76$ & $4.51 \pm 0.36$ & $7.45 \pm 0.47$ \\
\hline
\end{tabular}

Values are mean \pm SD of 8 independent calculations.

level of CML was further reduced to $41 \pm 0.71 \%$. The results are summarized in Table 4.

3.7. Histopathology of Rat Pancreas. The pancreatic tissues were typical in the control group with normal exocrine glands and islets of Langerhans (Figure 3(a)). However, in diabetic rats, the pancreatic tissues stained with $\mathrm{H} \& \mathrm{E}$ were found to be degenerative and necrotic along with shrinkage in Langerhans cells (Figure 3(b)). When diabetic rats were treated with $10 \mathrm{mM} \mathrm{AG}$, the occurrence of cellular fibrosis 
TABLE 3: Effects of AG and AG-Gnp on antioxidant defense system activity and pancreatic exocrine function in a diabetic rat model.

\begin{tabular}{lccccc}
\hline Group & MDA $\left(\mathrm{nmol} \mathrm{L}^{-1}\right)$ & SOD $\left(\mathrm{U} \mathrm{mL}^{-1}\right)$ & $\left.\mathrm{CAT}_{(\mathrm{U} \mathrm{mL}}^{-1}\right)$ & $\mathrm{GSH}_{\left(\mathrm{mg} \mathrm{dL}^{-1}\right)} \mathrm{AMS}\left(\mathrm{U} \mathrm{dL}^{-1}\right)$ \\
\hline Control & $2.45 \pm 0.68$ & $140.2 \pm 12.2$ & $4.22 \pm 1.87$ & $172.9 \pm 13.5$ & $719.8 \pm 23.7$ \\
Diabetic & $4.23 \pm 0.89$ & $201.9 \pm 21.7$ & $1.48 \pm 0.83$ & $123.4 \pm 12.5$ & $617.3 \pm 58.4$ \\
Diabetic+AG $(10 \mathrm{mMg})$ & $3.27 \pm 0.98$ & $136.3 \pm 56.4$ & $3.21 \pm 1.14$ & $155.8 \pm 42.3$ & $630.4 \pm 93.5$ \\
Diabetic+AG-GNP $\left(0.5 \mathrm{mM} \mathrm{kg}^{-1}\right)$ & $3.13 \pm 0.43$ & $130.2 \pm 43.6$ & $3.9 \pm 1.45$ & $167.8 \pm 34.6$ & $670.8 \pm 72.6$ \\
Diabetic+AG-GNP $\left(1 \mathrm{mM} \mathrm{kg}^{-1}\right)$ & $2.87 \pm 0.42$ & $136.6 \pm 25.2$ & $4.1 \pm 1.11$ & $178.1 \pm 34.6$ & $701.4 \pm 68.5$ \\
\hline
\end{tabular}

AG: aminoguanidine; AG-Gnp: aminoguanidine gold nanoparticle; MDA: malondialdehyde; SOD: superoxide dismutase; CAT: catalase; GSH: reduced glutathione; AMS: amylase. Values are the mean \pm SD of 8 independent calculations.

TABLE 4: Level of serum AGEs and CML-AGEs as measured by ELISA in diabetic and AG-Gnp-treated groups.

\begin{tabular}{lcc}
\hline Group & $\begin{array}{c}\text { Serum AGE level } \\
\left(\mu \mathrm{g} \mathrm{m}^{-1}\right)\end{array}$ & $\begin{array}{c}\text { Serum CML level } \\
\left(\mathrm{ng} \mathrm{mL}^{-1}\right)\end{array}$ \\
\hline Control & $1.21 \pm 0.23$ & $0.52 \pm 0.16$ \\
Diabetic & $5.83 \pm 0.45$ & $2.12 \pm 0.84$ \\
Diabetic+AG $(10 \mathrm{mM})$ & $4.92 \pm 0.63$ & $2.01 \pm 0.23$ \\
$\begin{array}{l}\text { Diabetic+AG-Gnp } \\
\left.(0.5 \mathrm{mM} \mathrm{kg})^{-1}\right)\end{array}$ & $4.14 \pm 0.53$ & $1.68 \pm 0.33$ \\
$\begin{array}{l}\text { Diabetic+Ag-Gnp } \\
\left(1.0 \mathrm{mM} \mathrm{kg}^{-1}\right)\end{array}$ & $3.21 \pm 0.71$ & $1.23 \pm 0.18$ \\
\hline
\end{tabular}

AG: aminoguanidine; AG-Gnp: aminoguanidine gold nanoparticle. Values are the mean $\pm \mathrm{SD}$ of 3 independent calculations.

suggested the prooxidant activity of AG (Figure 3(c)). However, when AG concentration was increased to $20 \mathrm{mmol} / \mathrm{L}$, a pathetic situation called perivascular infiltration of lymphocytes occurred (Figure 3(d)). These results are in agreement with the LDH assay, where we found cytotoxicity of AG at $10 \mathrm{mmol} / \mathrm{L}$ concentration. However, when $0.5 \mathrm{mmol} / \mathrm{L}$ AGGnp was given to diabetic rats, the disrupted islet boundaries and mass distribution of cytoplasm were improved, implying replenishment of islet structure and cell addition in the islets of diabetic rats (Figure 3(e)). Moreover, the administration of $1 \mathrm{mM}$ AG-Gnp markedly repaired this islet damage and improved the condition of islet cells and tissues (Figure 3(f)).

\section{Discussion}

The glycation-mediated AGE generation affects human physiology and is responsible for the pathogenesis of diabetesassociated secondary complications [40-42]. In this study, we evaluate the effect of gold nanoparticles (Gnp) on AGE generation during methylglyoxal- (MGO-) mediated glycation of human serum albumin (HSA) in vitro and diabetic rat model. Earlier, it has been studied that protein amino groups and gold colloids both interact with each other [43]. Although methodological studies demonstrated that larger nanoparticles could aggregate, it has not been reported that Gnp tends to aggregate while reacting with proteins [44]. Nanoparticles have a very large surface-to-volume ratio so that even a small amount of particles present extremely large surface areas available for protein binding [45]. Aggarwal et al. reported that proteins such as albumin, immunoglobulins, and fibrinogen associate with a wide range of nanoparticles of varying size and produce diverse molecular compositions [46]. As per previous reports, there are a variety of AGEs present in the circulatory system like CML, $N^{\varepsilon}$-(carboxymethyl)arginine, and $-N^{\varepsilon}$-(carboxyethyl)lysine [47]. Our results illustrated that the reactivity between MGO and HSA and the destabilization of HSA by MGO were decreased by AG-Gnp in a concentration-dependent manner. We hypothesized that AG-Gnp might compete with common glycation sites of HSA and obstruct the amino groups from reacting with MGO. A few of the free amino groups of protein can react with Gnp by donating electrons to the AG-Gnp, and AG-Gnp also can form electrostatic interactions with protonated amino groups. The HPLC data confirmed that the formation of AGEs shrank in the presence of AG-Gnp in a concentration-dependent manner. The drop in AGE levels might be due to the inhibition of MGO-mediated glycation of HSA by AG-Gnp, although AG $(10 \mathrm{mmol} / \mathrm{L})$ too moderately inhibited the formation of end-stage glycation adducts but to a lesser extent than AG-Gnp. However, the LDH assay discourages the use of AG because of its cytotoxic effect.

No matter the cause of diabetes, the result is always hyperglycemia. Studies have revealed hyperglycemia-mediated pathogenesis of microvascular complications such as neuropathy, nephropathy, and retinopathy. Various mechanisms have been proposed to explain the increased vascular risk associated with hyperglycemia. One such mechanism is the augmented formation of AGEs by the protein glycation. Clinically, type 1 diabetes is characterized by a typical autoimmune assault against the $\beta$-cells, inducing progressive $\beta$-cell death which is in line with the progressive decline in first-phase insulin secretion and causes insulin insufficiency and hyperglycemia [48].

In the alloxan-induced type 1 diabetic model, a significant increase in insulin and reduction in glucose levels were reported after AG-Gnp administration, along with an improved lipid profile. These results indicate the efficiency of AG-Gnp treatment in comparison to AG alone. Moreover, the results also implied AG-Gnp mediated protecting effect on pancreatic tissues and $\beta$-cell functioning, which were further validated by investigating the activity of pancreatic amylase (AMS) and the antioxidant defense system such as superoxide dismutase (SOD), catalase (CAT), and glutathione (GSH).

Firstly, we determined the malondialdehyde (MDA) concentration to inspect the level of lipid peroxidation and then measured the levels of antioxidants. Earlier studies have suggested increased SOD activity in diabetic rats, which might 


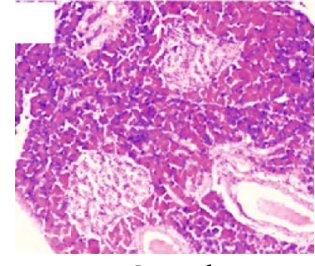

Control

(a)

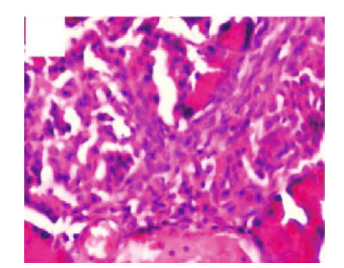

Diabetes + 10 mM AG; fibrosis

(c)

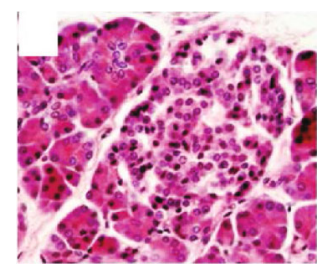

Diabetes + $0.5 \mathrm{mM}$ AG-Gnp

(e)

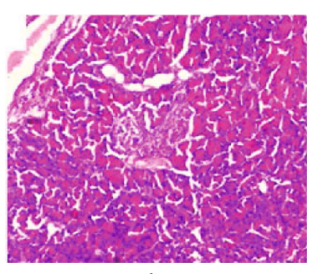

Diabetes

(b)

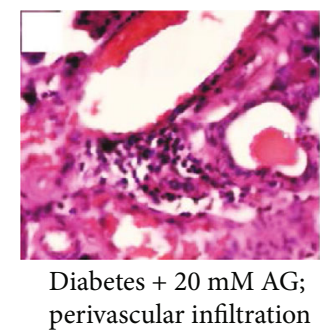

(d)

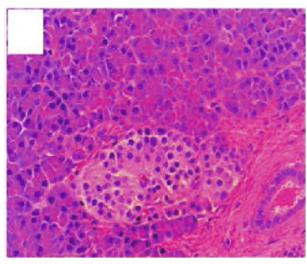

Diabetes $+1 \mathrm{mM}$ AG-Gnp

(f)

Figure 3: Effects of 10 and $20 \mathrm{mM}$ of AG and 0.5 and $1 \mathrm{mM}$ of AG-Gnp on pancreatic islet tissues in alloxan-induced diabetic rats. Photomicrographs showing pancreatic islet of the (a) normal control group, (b) diabetic group, (c) diabetic $+10 \mathrm{mM} / \mathrm{kg}$ AG group, (d) diabetic $+20 \mathrm{mM} / \mathrm{kg}$ AG group, (e) diabetic+0.5 mM AG-Gnp, and (f) diabetic+0.5 mM AG-Gnp. All experimental groups contain 6-8 rats.

be a protective measure against oxidative stress [49]. Our results show reduced SOD activity in animal groups that were treated with AG-Gnp. Moreover, CAT activity and GSH levels were also found to be increased in AG-Gnp-treated diabetic rats [50]. Reduced AMS activity is regarded as one of the factors showing impairment in the exocrine function of the pancreas [51]. In our experiment, AG-Gnp was more effective in improving the pancreatic exocrine function in comparison to AG alone [52]. Furthermore, the histopathological analysis provides evidence of improvement in pancreas tissue and viability of $\beta$-cell produced by AG-Gnp. Thus, we conclude that all the parameters discussed in this study implied the effectiveness of AG-Gnp in comparison to that of AG.

\section{Conclusion}

The present study provides an insight to understand the potential role of aminoguanidine-bioconjugated gold nanoparticles (AG-Gnp) in reducing diabetes-associated secondary complications by inhibiting glycation and generation of AGEs. The antiglycation property of AG-Gnp might provide a link that facilitates the glycobiologists to explore new therapeutic applications for halting the menace of AGEs. This novel approach increases the efficacy of aminoguanidine at reduced concentration with no toxicity and might effectively minimize the use of other antiglycation drugs that are toxic at high concentrations.

\section{Future Prospects}

Gold nanoparticles (Gnp) are among the most commonly used nanostructures in biological applications that are used in several therapeutic applications for the treatment of various diseases. Therefore, the bioconjugation of antiglycating agents such as aminoguanidine, pyridoxamine, and metformin with Gnp would help to reduce the cytotoxic concentrations of these drugs nowadays. Moreover, the bioconjugation of plant-derived natural products may also be done in order to get rid of the complications associated with the glycation reaction. Therefore, the need of the hour is to do the bioconjugation of natural products as well. This novel approach will be of prudent commercial value as no reports are there to inhibit the glycation reaction using bioconjugation of these drugs using Gnp. Moreover, the direct effect of Gnp on glycation status would also add reliable implications in its inhibition. The research on inhibition of glycation is at the nascent stage, and very few studies have been performed. The PubMed search itself shows the reality that subtle data is available in this regard till now. Therefore, the prospect of our investigation is reasonably alluring and might add more insights to stop the menace of glycation in the near future. 


\section{Abbreviations}

$\begin{array}{ll}\text { AGEs: } & \text { Advanced glycation end products } \\ \text { AG: } & \text { Aminoguanidine } \\ \text { AG-Gnp: } & \text { Aminoguanidine-gold nanoparticles } \\ \text { FL: } & \text { E-Fructosyl-L-lysine } \\ \text { GO: } & \text { Glyoxal } \\ \text { Gnp: } & \text { Gold nanoparticles } \\ \text { HPLC: } & \text { High performance liquid chromatography } \\ \text { HSA: } & \text { Human serum albumin } \\ \text { MGO: } & \text { Methylglyoxal } \\ \text { CML: } & \text {-N }{ }^{\varepsilon} \text {-(Carboxymethyl)lysine } \\ \text { CEL: } & \text {-N }{ }^{\varepsilon} \text {-(Carboxyethyl)lysine } \\ \text { LDH: } & \text { Lactate dehydrogenase } \\ \text { OPA: } & \text { o-Phthalaldehyde } \\ \text { ROS: } & \text { Reactive oxygen species } \\ \text { RCS: } & \text { Reactive carbonyl species } \\ \text { RP-HPLC: } & \text { Reverse phase-high performance liquid } \\ & \text { chromatography } \\ \text { 3-DG: } & \text { 3-Deoxyglucosone } \\ \text { DTNB: } & \text { 5,5'-Dithio-bis-[2-nitrobenzoic acid] } \\ \text { EDC: } & \text { 1-Ethyl-3-(3-dimethylaminopropyl)- } \\ & \text { carbodiimide. }\end{array}$

\section{Data Availability}

The data for this article is within the manuscript.

\section{Conflicts of Interest}

The authors declare that they have no conflicts of interest with the contents of this article.

\section{Acknowledgments}

This research has been funded by the Research Deanship in the University of Hail, Saudi Arabia, through project number RG-20029.

\section{References}

[1] S. Rehman, M. Faisal, A. A. Alatar, and S. Ahmad, "Physicochemical changes induced in serum proteins, immunoglobulin- $G$ and fibrinogen by reactive carbonyl species, methylglyoxal," Current Protein \& Peptide Science, vol. 21, pp. 916-923, 2019.

[2] S. Ahmad, H. Khan, U. Shahab et al., "Protein oxidation: an overview of metabolism of sulphur containing amino acid, cysteine," Frontiers in Bioscience (Scholar Edition), vol. 9, no. 1, pp. 71-87, 2017.

[3] S. Ahmad, K. Dixit, U. Shahab, K. Alam, and A. Ali, "Genotoxicity and immunogenicity of DNA-advanced glycation end products formed by methylglyoxal and lysine in presence of $\mathrm{Cu}^{2+}$, Biochemical and Biophysical Research Communications, vol. 407, no. 3, pp. 568-574, 2011.

[4] S. Ahmad, Z. Siddiqui, S. Rehman et al., "A glycation angle to look into the diabetic vasculopathy: cause and cure," Current Vascular Pharmacology, vol. 15, no. 4, pp. 352-364, 2017.

[5] I. Mustafa, S. Ahmad, K. Dixit, J. Ahmad, and A. Ali, "Glycated human DNA is a preferred antigen for anti-DNA antibodies in diabetic patients," Diabetes Research and Clinical Practice, vol. 95, no. 1, pp. 98-104, 2012.

[6] S. Ahmad and S. Rehman, "Impact of reactive dicarbonyls on biological macromolecules-role in metabolic disorders," Current Protein \& Peptide Science, vol. 21, no. 9, pp. 844-845, 2020.

[7] N. Katakami, "Mechanism of development of atherosclerosis and cardiovascular disease in diabetes mellitus," Journal of Atherosclerosis and Thrombosis, vol. 25, no. 1, pp. 27-39, 2018.

[8] H. M. Semchyshyn, "Reactive carbonyl species in vivo: generation and dual biological effects," The Scientific World Journal, vol. 2014, Article ID 417842, 10 pages, 2014.

[9] S. Ahmad, M. Y. Khan, Z. Rafi et al., "Oxidation, glycation and glycoxidation-The vicious cycle and lung cancer," Seminars in Cancer Biology, vol. 49, pp. 29-36, 2018.

[10] E. Selvin, M. W. Steffes, H. Zhu et al., "Glycated hemoglobin, diabetes, and cardiovascular risk in nondiabetic adults," New England Journal of Medicine, vol. 362, no. 9, pp. 800-811, 2010.

[11] T. Bilova, E. Lukasheva, D. Brauch et al., "Patterns and Mechanisms of Plant Glycation," Journal of Biological Chemistry, vol. 291, no. 14, pp. 7621-7636, 2016.

[12] S. Ahmad, H. Khan, Z. Siddiqui et al., "AGEs, RAGEs and sRAGE; friend or foe for cancer," Seminars in Cancer Biology, vol. 49, pp. 44-55, 2018.

[13] F. Akhter, M. S. Khan, U. Shahab, and S. Ahmad, "Bio-physical characterization of ribose induced glycation: a mechanistic study on DNA perturbations," International Journal of Biological Macromolecules, vol. 58, pp. 206-210, 2013.

[14] M. Fournet, F. Bonté, and A. Desmoulière, "Glycation damage: a possible hub for major pathophysiological disorders and aging," Aging and Disease, vol. 9, no. 5, pp. 880-900, 2018.

[15] P. Jud and H. Sourij, "Therapeutic options to reduce advanced glycation end products in patients with diabetes mellitus: a review," Diabetes Research and Clinical Practice, vol. 148, pp. 54-63, 2019.

[16] V. V. Nimbalkar, R. V. Mandlik, S. R. Naik, and A. Maseeh, "Nonenzymatic glycosylation: a biochemical link between chronic hyperglycemia and pathophysiologic processes associated with diabetic complications and aging related debilities," Biomedicine \& Aging Pathology, vol. 2, no. 4, pp. 133-142, 2012.

[17] A. Soboleva, G. Mavropulo-Stolyarenko, T. Karonova et al., "Multiple glycation sites in blood plasma proteins as an integrated biomarker of type 2 diabetes mellitus," International Journal of Molecular Sciences, vol. 20, no. 9, p. 2329, 2019.

[18] M. Brownlee, H. Vlassara, A. Kooney, P. Ulrich, and A. Cerami, "Aminoguanidine prevents diabetes-induced arterial wall protein cross-linking," Science, vol. 232, no. 4758, pp. 1629-1632, 1986.

[19] S. Ahmad, U. Shahab, M. H. Baig et al., "Inhibitory effect of metformin and pyridoxamine in the formation of early, intermediate and advanced glycation end-products," PLoS One, vol. 8, no. 9, article e72128, 2013.

[20] N. Ahmed, "Advanced glycation endproducts-role in pathology of diabetic complications," Diabetes Research and Clinical Practice, vol. 67, no. 1, pp. 3-21, 2005.

[21] D. Edelstein and M. Brownlee, "Aminoguanidine ameliorates albuminuria in diabetic hypertensive rats," Diabetologia, vol. 35, no. 1, pp. 96-97, 1992. 
[22] M. Shah, V. D. Badwaik, and R. Dakshinamurthy, "Biological applications of gold nanoparticles," Journal of Nanoscience and Nanotechnology, vol. 14, no. 1, pp. 344-362, 2014.

[23] S. A. Bansal, V. Kumar, J. Karimi, A. P. Singh, and S. Kumar, "Role of gold nanoparticles in advanced biomedical applications," Nanoscale Advances, vol. 2, no. 9, pp. 3764-3787, 2020.

[24] P. Mukherjee, R. Bhattacharya, N. Bone et al., "Potential therapeutic application of gold nanoparticles in B-chronic lymphocytic leukemia (BCLL): enhancing apoptosis," Journal of Nanobiotechnology, vol. 5, no. 1, p. 4, 2007.

[25] E. S. Ali, S. M. Sharker, M. T. Islam et al., "Targeting cancer cells with nanotherapeutics and nanodiagnostics: current status and future perspectives," Seminars in Cancer Biology, vol. 69, pp. 52-68, 2020.

[26] M. E. Aubin-Tam and K. Hamad-Schifferli, "Structure and function of nanoparticle-protein conjugates," Biomedical Materials, vol. 3, no. 3, article 034001, 2008.

[27] S. Ahmad, M. S. Khan, F. Akhter et al., "Glycoxidation of biological macromolecules: a critical approach to halt the menace of glycation," Glycobiology, vol. 24, no. 11, pp. 979-990, 2014.

[28] Y. Wang, H. Wang, M. S. Khan, F. M. Husain, S. Ahmad, and L. Bian, "Bioconjugation of gold nanoparticles with aminoguanidine as a potential inhibitor of non-enzymatic glycation reaction," Journal of Biomolecular Structure and Dynamics., vol. 39, no. 6, pp. 2014-2020, 2021.

[29] S. A. Kumar, M. K. Abyaneh, S. W. Gosavi, S. K. Kulkarni, A. Ahmad, and M. I. Khan, "Sulfite reductase-mediated synthesis of gold nanoparticles capped with phytochelatin," Biotechnology and Applied Biochemistry, vol. 47, no. 4, pp. 191195, 2007.

[30] G. T. Hermanson, Bioconjugate Techniques, Academic press, 2nd edition, 2013.

[31] S. Ahmad, F. Akhter, U. S. Moinuddin, and M. S. Khan, "Studies on glycation of human low density lipoprotein: a functional insight into physico-chemical analysis," International Journal of Biological Macromolecules, vol. 62, pp. 167-171, 2013.

[32] U. Shahab, S. Tabrez, M. S. Khan et al., "Immunogenicity of DNA-advanced glycation end product fashioned through glyoxal and arginine in the presence of $\mathrm{Fe} 3+$ : its potential role in prompt recognition of diabetes mellitus auto-antibodies," Chemico-Biological Interactions, vol. 219, pp. 229240, 2014.

[33] C. Delgado-Andrade, I. Seiquer, M. P. Navarro, and F. J. Morales, "Maillard reaction indicators in diets usually consumed by adolescent population," Molecular Nutrition \& Food Research, vol. 51, no. 3, pp. 341-351, 2007.

[34] D. Iqbal, M. S. Khan, M. S. Khan, S. Ahmad, M. S. Hussain, and M. Ali, "Bioactivity guided fractionation and hypolipidemic property of a novel HMG-CoA reductase inhibitor from Ficus virens Ait," Lipids in Health and Disease, vol. 14, no. 1, p. 15, 2015.

[35] M. Pourghasem, E. Nasiri, and H. Shafi, "Early renal histological changes in alloxan-induced diabetic rats," International Journal of Molecular and Cellular Medicine, vol. 3, no. 1, pp. 11-15, 2014.

[36] H. Khan, M. S. Khan, and S. Ahmad, "The in vivo and in vitro approaches for establishing a link between advanced glycation end products and lung cancer," Journal of Cellular Biochemistry, vol. 119, no. 11, pp. 9099-9109, 2018.
[37] J. Armato, R. Ruby, and G. Reaven, "Plasma triglyceride determination can identify increased risk of statin-induced type 2 diabetes: a hypothesis," Atherosclerosis, vol. 239, no. 2, pp. 401-404, 2015.

[38] M. Otero-Losada, G. Cao, J. González et al., "Functional and morphological changes in endocrine pancreas following cola drink consumption in rats," PLoS One, vol. 10, no. 3, article e0118700, 2015.

[39] K. Rashid and P. C. Sil, "Curcumin enhances recovery of pancreatic islets from cellular stress induced inflammation and apoptosis in diabetic rats," Toxicology and Applied Pharmacology, vol. 282, no. 3, pp. 297-310, 2015.

[40] A. Khanam, S. Ahmad, A. Husain, S. Rehman, A. Farooqui, and M. A. Yusuf, "Glycation and antioxidants: hand in the glove of antiglycation and natural antioxidants," Current Protein and Peptide Science, vol. 21, no. 9, pp. 899-915, 2020.

[41] A. Khanam, S. Alouffi, S. Rehman, I. A. Ansari, U. Shahab, and S. Ahmad, "An in vitro approach to unveil the structural alterations in d-ribose induced glycated fibrinogen," Journal of Biomolecular Structure and Dynamics, pp. 1-15, 2020.

[42] S. Ahmad, U. S. Moinuddin, S. Habib, M. S. Khan, K. Alam, and A. Ali, "Glycoxidative damage to human DNA: neoantigenic epitopes on DNA molecule could be a possible reason for autoimmune response in type 1 diabetes," Glycobiology, vol. 24, no. 3, pp. 281-291, 2014.

[43] R. GhoshMoulick, J. Bhattacharya, C. K. Mitra, S. Basak, and A. K. Dasgupta, "Protein seeding of gold nanoparticles and mechanism of glycation sensing," Nanomedicine: Nanotechnology, Biology and Medicine, vol. 3, no. 3, pp. 208-214, 2007.

[44] C. Seneviratne, R. Narayanan, W. Liu, and J. A. Dain, "The in vitro inhibition effect of $2 \mathrm{~nm}$ gold nanoparticles on nonenzymatic glycation of human serum albumin," Biochemical and Biophysical Research Communications, vol. 422, no. 3, pp. 447-454, 2012.

[45] J. Klein, "Probing the interactions of proteins and nanoparticles," Proceedings of the National Academy of Sciences, vol. 104, no. 7, pp. 2029-2030, 2007.

[46] P. Aggarwal, J. B. Hall, C. B. McLeland, M. A. Dobrovolskaia, and S. E. McNeil, "Nanoparticle interaction with plasma proteins as it relates to particle biodistribution, biocompatibility and therapeutic efficacy," Advanced Drug Delivery Reviews, vol. 61, no. 6, pp. 428-437, 2009.

[47] U. Greifenhagen, A. Frolov, M. Blüher, and R. Hoffmann, "Site-specific analysis of advanced glycation end products in plasma proteins of type 2 diabetes mellitus patients," Analytical and Bioanalytical Chemistry, vol. 408, no. 20, pp. 55575566, 2016.

[48] M. Cnop, N. Welsh, J. C. Jonas, A. Jörns, S. Lenzen, and D. L. Eizirik, "Mechanisms of pancreatic $\beta$-cell death in type 1 and type 2 diabetes: many differences, few similarities," Diabetes, vol. 54, Supplement 2, pp. S97-S107, 2005.

[49] S. Tas, E. Sarandol, S. Z. Ayvalik, Z. Serdar, and M. Dirican, "Vanadyl sulfate, taurine, and combined vanadyl sulfate and taurine treatments in diabetic rats: effects on the oxidative and antioxidative systems," Archives of Medical Research, vol. 38, no. 3, pp. 276-283, 2007.

[50] M. Hussin, A. Abdul-Hamid, S. Mohamad, N. Saari, M. Ismail, and M. H. Bejo, "Protective effect of Centella asiatica extract and powder on oxidative stress in rats," Food Chemistry, vol. 100, no. 2, pp. 535-541, 2007. 
[51] R. P. Robertson and J. S. Harmon, "Diabetes, glucose toxicity, and oxidative stress: a case of double jeopardy for the pancreatic islet $\beta$ cell," Free Radical Biology and Medicine, vol. 41, no. 2, pp. 177-184, 2006.

[52] T. S. Dhas, V. G. Kumar, V. Karthick, K. Vasanth, G. Singaravelu, and K. Govindaraju, "Effect of biosynthesized gold nanoparticles by Sargassum swartzii in alloxan induced diabetic rats," Enzyme and Microbial Technology, vol. 95, pp. 100-106, 2016. 